\title{
The effects of body weight on airway calibre
}

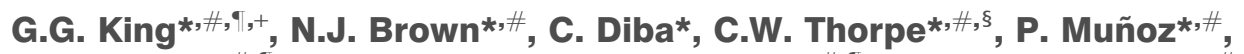

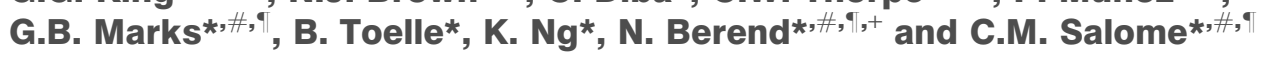

ABSTRACT: Increased wheeze and asthma diagnosis in obesity may be due to reduced lung volume with subsequent airway narrowing.

Asthma (wheeze and airway hyperresponsiveness), functional residual capacity (FRC) and airway conductance (Gaw) were measured in 276 randomly selected subjects aged 28-30 yrs. Data were initially adjusted for smoking and asthma before examining relationships between weight and FRC (after adjustment for height), and between body mass index (BMI= weight $\cdot$ height $^{-2}$ ) and Gaw (after adjustment for FRC) by multiple linear regression, separately for females and males.

For males and females, BMI ( $\pm 95 \%$ confidence interval) was $27.0 \pm 4.6 \mathrm{~kg} \cdot \mathrm{m}^{-2}$ and $25.6 \pm 6.0 \mathrm{~kg} \cdot \mathrm{m}^{-2}$ respectively, Gaw was $0.64 \pm 0.04 \mathrm{~L} \cdot \mathrm{s}^{-1} \cdot \mathrm{cmH}_{2} \mathrm{O}^{-1}$ and $0.57 \pm 0.03 \mathrm{~L} \cdot \mathrm{s}^{-1} \cdot \mathrm{cmH}_{2} \mathrm{O}^{-1}$, and FRC was $85.3 \pm 3.4$ and $84.0 \pm 2.9 \%$ of predicted. Weight correlated independently with FRC in males and females. BMI correlated independently and inversely with Gaw in males, but only weakly in females.

In conclusion, obesity is associated with reduced lung volume, which is linked with airway narrowing. However, in males, airway narrowing is greater than that due to reduced lung volume alone. The mechanisms causing airway narrowing and sex differences in obesity are unknown.

KEYWORDS: Airway conductance, airway hyperresponsiveness, asthma, lung volume measurements, obesity

0 besity is an increasing problem in Western societies, with substantial effects on health outcomes. There is increasing evidence that the prevalence of both wheezing and doctor-diagnosed asthma is significantly increased in obese people [1-7]. Results of the current authors studies in large, randomly selected population samples of Australian adults have shown that obesity, defined as body mass index $(\mathrm{BMI})>30 \mathrm{~kg} \cdot \mathrm{m}^{-2}$, is associated with a two to three-fold increase in the risk of wheezing, with diagnosed asthma and the use of asthma medication [8]. Results of some recent studies also show that obesity is associated with an increased risk of airway hyperresponsiveness (AHR) [3, 5].

The association of obesity with both wheezing and AHR implies that it affects airway calibre. The link between obesity and the decreased lung volume at which breathing occurs (functional residual capacity (FRC)) is well documented [912], and is probably due to the pressure of abdominal contents on the diaphragm. There is a linear relationship between lung volume and airway calibre (airway conductance (Gaw)) [13], so any reduction in lung volume is likely to cause a reduction in airway calibre. Indeed, results of two previously published studies suggest that reduced airway calibre in obesity is due simply to reduced FRC [11, 14]. However, the excess in asthma diagnosis and symptoms in obese subjects suggests that there might be greater airway narrowing than could be explained simply by reduced airway calibre alone.

In winter 2002, the present authors undertook a follow-up study of the Belmont cohort (New South Wales, Australia) [15], in which airway calibre (Gaw) and static lung volumes were measured by body plethysmography in a general population sample of young adults aged 2830 yrs. This narrow age range meant that the potentially confounding effects of age on the elastic properties of the lung and, hence, on airway calibre, were not present. This study tested the hypothesis that increasing BMI causes airway narrowing over and above that caused by reduced lung volume alone.

\section{METHODS}

The subjects were members of a cohort of 718 children aged 8-10 yrs who were recruited in the winter months (June and July) of 1982 from a random selection of primary schools in the Belmont region of New South Wales, Australia
AFFILIATIONS

*Woolcock Institute of Medical Research,

\#Cooperative Research Centre for Asthma, Camperdown,

"University of Sydney, Sydney, and +Dept of Respiratory Medicine, Royal North Shore Hospital, St. Leonards, New South Wales, Australia.

${ }^{\S}$ Bioengineering Institute, University of Auckland, Auckland, New Zealand.

\section{CORRESPONDENCE}

G.G King, Woolcock Institute of Medical Research, Dept of Respiratory Medicine, Royal North Shore Hospital, Pacific Highway, St. Leonards 2065, Australia. Fax: 61299066391

E-mail: ggk@woolcock.org.au

Received:

September 072004

Accepted after revision:

December 022004

SUPPORT STATEMENT

This study was supported by a National Health and Medical Research Council Grant No. 153809, University of Sydney Medical Foundation Grant and Cooperative Research Centre for Asthma (Project 12a).

In the past 5 yrs, G.G. King, N.J. Brown and G.B. Marks have received sponsorships (flights and accommodation) from AstraZeneca, GlaxoSmithKline and Boehringer

Ingelheim for attending scientific meetings and honoraria for providing services for local respiratory medicine meetings. The Woolcock Institute (Camperdown, Australia)

received unrestricted grants from the aforementioned companies of which the authors' research groups received an allocation to support research studies. G.B. Marks, G.G. King and $N$. Berend are members of steering committees for the aforementioned companies.

European Respiratory Journal Print ISSN 0903-1936

Online ISSN 1399-3003 
[16]. In the present study, 322 members of the cohort who completed a questionnaire and underwent skin-prick tests and histamine bronchial challenge tests during the winter months of 2002 were included. Subjects were aged 28-30 yrs at the time of study. The authors determined airway calibre (Gaw) in relation to lung volume, and examined the relationships to BMI after adjusting for potential confounding factors. This study was approved by the Human Ethics Review Committee of the University of Sydney, Sydney, Australia (protocol number 02/02/58), and all subjects gave written informed consent.

\section{Questionnaire and skin-prick tests}

Subjects completed questionnaires about asthma diagnosis, respiratory symptoms and medication use. Skin-prick tests were performed using a panel of eight common aeroallergens and included a positive and negative control. A positive skinprick test was defined as an average weal diameter of $\geqslant 3 \mathrm{~mm}$.

\section{Spirometry and bronchial challenge tests}

Spirometry was measured using dry rolling seal spirometers (S\&M; Mijnhardt BV, Bunnik, Holland), calibrated daily. Bronchial challenges were performed using the rapid method [17], in which histamine diphosphate was administered by use of DeVilbiss No. 45 hand-held nebulisers (DeVilbiss Health Care Inc., Sommerset, PA, USA) in doses ranging 0.03$3.9 \mu \mathrm{mol}$ histamine. The forced expiratory volume in one second (FEV1) was measured $30 \mathrm{~s}$ later and was followed immediately by the next dose. The test was stopped if the FEV1 fell by $\geqslant 20 \%$ of the post-saline value or if all histamine dose steps to $3.9 \mu \mathrm{mol}$ had been administered. Salbutamol $(200 \mu \mathrm{g})$ was administered at the end of the challenge to subjects who had a decrease in FEV1 of $\geqslant 10 \%$. Short-acting $\beta$-agonists were withheld for $6 \mathrm{~h}$ and long-acting $\beta$-agonists for $24 \mathrm{~h}$ prior to testing. If the post-saline FEV1 was $<70 \%$ of predicted, then patients underwent a bronchodilator reversibility test with only $200 \mu \mathrm{g}$ salbutamol. AHR was present if there was a $\geqslant 20 \%$ decrease in FEV1 after inhalation of $\leqslant 3.9 \mu \mathrm{mol}$ of histamine, or if there was $\geqslant 15 \%$ increase in FEV1 after inhalation of $200 \mu \mathrm{g}$ salbutamol. The predicted values of KNUDSON et al. [18] were used.

\section{Body plethysmography}

Gaw, the lung volume at which Gaw was measured (thoracic gas volume $(\mathrm{Vtg}))$ and the subdivisions of lung volume were measured using a constant-volume body plethysmograph (Autobox 6200 DL; Sensormedics, Yorba Linda, CA, USA), which was calibrated twice daily. Subjects supported their cheeks with their hands, wore a noseclip and panted gently at $\sim 1 \mathrm{~Hz}$ while the shutter was opened and closed, then inhaled slowly to total lung capacity (TLC) and then exhaled slowly to residual volume. All flow versus plethysmograph pressure loops and mouth pressure versus plethysmograph pressure loops, from which Gaw and Vtg were calculated, were visually checked and aberrant loops were discarded. At least three reproducible measurements were obtained, from which the average TLC and FRC, and the best vital capacity were selected. The predicted values from CRAPO et al. [19] for lung volumes and BRISCOE and Du BoIs [20] for Gaw were used.

\section{Data analyses}

All data are presented as mean $\pm 95 \%$ confidence intervals unless otherwise specified. Current asthma was defined as the presence of self-reported wheeze in the last year and AHR [21]. The mean BMI in the presence or absence of wheeze, AHR and current asthma were compared using unpaired t-tests. The effect of weight or BMI on FRC and Gaw, after adjustment for potential confounders, was tested using a two-stage regression modelling approach. In the first stage, the association of FRC and Gaw with smoking (current smoking status, years smoked and number of cigarettes smoked per day) and current asthma status was tested. Where a significant association was demonstrated, the residuals after adjustment for confounding were used in subsequent models. In the absence of any significant association, raw values were used in the second stage. Age was not included as a confounder in either of these models due to the small age range of the subjects. In the second-stage model for FRC, first-stage outcome was regressed on height, which is known to be correlated with FRC, and weight, which was included as an indicator of obesity. In the second-stage model for Gaw, the first-stage outcome for this variable was regressed on $\mathrm{Vtg}$, which is known to be correlated with Gaw, and BMI, which was included as an indicator of obesity. Predictors were selected using a stepwise procedure. The effect of sex on the association between obesity and the lung function outcomes was tested using interaction terms and, where these were significant, sex-specific models were fitted.

\section{RESULTS}

The characteristics of the cohort are shown in table 1 . There were satisfactory Gaw measurements and bronchial challenges to histamine (or bronchodilator reversibility tests) in 276 subjects, with $27(9.8 \%)$ having AHR. There were no differences in mean BMI of the $74(27 \%)$ subjects who had

\begin{tabular}{lccc} 
TABLE 1 & Subject characteristics and lung function \\
& Male & Female & Total \\
\hline & & & \\
Subjects n & $139(50)$ & $137(50)$ & 276 \\
Atopy & $77(58)$ & $48(38)$ & $125(48)$ \\
FEV $\mathbf{1} \%$ pred & $99.9 \pm 2$ & $107.5 \pm 2$ & $103.3 \pm 1.1$ \\
FEV1/FVC \% & $82.7 \pm 1.1$ & $84.9 \pm 1.0$ & $83.8 \pm 0.7$ \\
Wheeze & $34(25)$ & $40(29)$ & $74(27)$ \\
AHR & $12(9)$ & $15(11)$ & $27(10)$ \\
Current asthma & $8(6)$ & $14(10)$ & $22(8)$ \\
Gaw L. $\mathbf{s}^{-1} \cdot \mathbf{c m H}_{\mathbf{2}} \mathbf{O}^{-\mathbf{1}}$ & $0.64 \pm 0.04$ & $0.58 \pm 0.03$ & $0.61 \pm 0.03$ \\
sGaw \% pred & $72.3 \pm 4.6$ & $68.7 \pm 4.0$ & $70.5 \pm 3.0$ \\
FRC \% pred & $85.3 \pm 3.4$ & $84.0 \pm 2.9$ & $84.7 \pm 2.3$ \\
Smoking & $36(26)$ & $40(29)$ & $76(28)$ \\
Height $\mathbf{~ c m ~}$ & $178.2 \pm 1.1$ & $164.8 \pm 1.1$ & \\
Weight kg & $85.4 \pm 2.7$ & $68.4 \pm 2.6$ & \\
BMI & $26.8 \pm 0.7$ & $25.2 \pm 1.0$ & \\
\hline
\end{tabular}

Data are presented as $\mathrm{n}(\%)$ or mean $\pm 95 \%$ confidence interval. FEV 1 : forced expiratory volume in one second; \% pred: \% predicted; FVC: forced vital capacity; AHR: airway hyperresponsiveness: Gaw: airway conductance; sGaw: specific airway conductance; FRC: functional residual capacity; BMI: body mass index. 
wheeze $\left(26.8 \pm 1.5 \mathrm{~kg} \cdot \mathrm{m}^{-2}\right)$ compared with those who did not $\left(25.8 \pm 0.6 \mathrm{~kg} \cdot \mathrm{m}^{-2} ; \mathrm{p}>0.05\right)$; of the $27(10 \%)$ subjects who had AHR $\left(26.5 \pm 2.7 \mathrm{~kg} \cdot \mathrm{m}^{-2}\right)$ compared with those who did not $\left(26.0 \pm 0.6 \mathrm{~kg} \cdot \mathrm{m}^{-2} ; \mathrm{p}>0.05\right)$; or of the $22(8 \%)$ subjects who had current asthma $\left(27.5 \pm 3.1 \mathrm{~kg} \cdot \mathrm{m}^{-2}\right)$ compared with those who did not $\left(25.9 \pm 0.6 \mathrm{~kg} \cdot \mathrm{m}^{-2} ; \mathrm{p}>0.05\right)$.

\section{First-stage regression: adjustment for disease confounders}

There were no significant independent associations between the potential confounders (smoking and current asthma) and FRC $\left(\mathrm{r}^{2}=0.01, \mathrm{p}=0.49\right)$; therefore, no adjustment of FRC was necessary. Current asthma, but not smoking, was significantly associated with Gaw $\left(r^{2}=0.03, p=0.0047\right)$.Thus, Gaw residuals adjusted for current asthma were used in subsequent regressions.

\section{Body mass index and lung volume}

Interaction terms demonstrated that the associations between FRC and both height and weight were significantly influenced by sex (table 2); therefore, models for FRC were fitted separately for each sex (table 3). In males, the estimated effect of weight (independent of the effect of height) on FRC was a $30-\mathrm{mL}$ decrease for each $\mathrm{kg}$ increase in weight, explaining $14 \%$ of the variance in FRC $(p<0.0001)$. In females, the estimated independent effect of weight was a $20-\mathrm{mL}$ decrease per $\mathrm{kg}$ increase in weight, explaining $32 \%$ of the variance in FRC $(p<0.0001)$.

\section{Body mass index and airway calibre}

Interaction terms demonstrated that the associations between BMI and Gaw were significantly influenced by sex $(p=0.004)$; therefore, models for FRC were fitted separately for each sex. The results of univariate linear regressions for males and

\begin{tabular}{|c|c|c|c|c|}
\hline \multirow{2}{*}{$\begin{array}{l}\text { TABLE } 2 \\
\text { Outcome }\end{array}$} & \multicolumn{4}{|c|}{$\begin{array}{l}\text { Univariate associations between predictors (body } \\
\text { mass index (BMI), height and weight) and } \\
\text { outcomes (functional residual capacity (FRC) anc } \\
\text { airway conductance (Gaw)) }\end{array}$} \\
\hline & Predictor & Effect ${ }^{\#}$ & $\mathbf{R}^{2 *}$ & p-value \\
\hline \multicolumn{5}{|l|}{ Males } \\
\hline \multirow[t]{3}{*}{$\mathrm{FRC}^{+}$} & $\mathrm{BMI} \mathrm{kg} \cdot \mathrm{m}^{-2}$ & $-0.10 \pm 0.03$ & 0.33 & $<0.0001$ \\
\hline & Height $\mathrm{cm}$ & $0.04 \pm 0.02$ & 0.13 & $<0.0001$ \\
\hline & Weight kg & $-0.017 \pm 0.07$ & 0.14 & $<0.0001$ \\
\hline \multirow[t]{4}{*}{$\mathrm{Gaw}^{\S}$} & $\mathrm{BMI} \mathrm{kg} \cdot \mathrm{m}^{-2}$ & $-0.02 \pm 0.01$ & 0.13 & $<0.0001$ \\
\hline & Height cm & $0.0002 \pm 0.000$ & 0.00 & 0.96 \\
\hline & Weight kg & $-0.005 \pm 0.003$ & 0.10 & 0.0001 \\
\hline & $\operatorname{Vtg} L$ & $0.09 \pm 0.05$ & 0.09 & 0.0004 \\
\hline \multicolumn{5}{|l|}{ Females } \\
\hline \multirow[t]{3}{*}{$\mathrm{FRC}^{+}$} & $\mathrm{BMI} \mathrm{kg} \cdot \mathrm{m}^{-2}$ & $-0.06 \pm 0.01$ & 0.48 & $<0.0001$ \\
\hline & Height cm & $0.037 \pm 0.014$ & 0.18 & $<0.0001$ \\
\hline & Weight kg & $-0.02 \pm 0.005$ & 0.32 & $<0.0001$ \\
\hline \multirow[t]{4}{*}{$\mathrm{Gaw}^{\S}$} & $\mathrm{BMI} \mathrm{kg} \cdot \mathrm{m}^{-2}$ & -0.006 & 0.03 & 0.03 \\
\hline & Height $\mathrm{cm}$ & $0.007 \pm 0.005$ & 0.05 & 0.008 \\
\hline & Weight kg & $-0.001 \pm 0.002$ & 0.01 & 0.2 \\
\hline & $V \operatorname{tg} L$ & $0.03 \pm 0.06$ & 0.01 & 0.3 \\
\hline
\end{tabular}

Data are presented as mean $\pm 95 \%$ confidence interval, unless otherwise stated. Vtg: thoracic gas volume. ${ }^{\#}$ : effect sizes unadjusted for effects of other predictors; $\uparrow$ : unadjusted proportion of variance explained by the predictor; + : effect measured in $\mathrm{L} ;{ }^{\S}$ : effect measured in $\mathrm{L} \cdot \mathrm{s}^{-1} \cdot \mathrm{CmH}_{2} \mathrm{O}^{-1}$.

\begin{tabular}{|c|c|c|c|c|}
\hline TABLE 3 & \multicolumn{4}{|c|}{$\begin{array}{l}\text { Multivariate associations between predictors } \\
\text { (body mass index (BMI), height and weight) and } \\
\text { outcomes (functional residual capacity (FRC) and } \\
\text { airway conductance (Gaw)) }\end{array}$} \\
\hline Outcome & Predictor $\#$ & Effect & Partial R & $+p$-value \\
\hline \multicolumn{5}{|l|}{ Males } \\
\hline \multirow[t]{2}{*}{$\mathrm{FRC}^{\S}$} & Height $\mathrm{cm}$ & $0.08 \pm 0.02$ & 0.39 & $<0.0001$ \\
\hline & Weight kg & $-0.03 \pm 0.006$ & 0.14 & $<0.0001$ \\
\hline \multirow[t]{2}{*}{$\operatorname{Gaw}^{f}$} & BMI $\mathrm{kg} \cdot \mathrm{m}^{-2}$ & $-0.017 \pm 0.010$ & 0.13 & $<0.0001$ \\
\hline & $V \operatorname{tg} L$ & $0.06 \pm 0.05$ & 0.03 & 0.035 \\
\hline \multicolumn{5}{|l|}{ Females } \\
\hline \multirow[t]{2}{*}{$\mathrm{FRC}^{\S}$} & Height $\mathrm{cm}$ & $0.04 \pm 0.01$ & 0.24 & $<0.0001$ \\
\hline & Weight kg & $-0.02 \pm 0.004$ & 0.32 & $<0.0001$ \\
\hline $\mathrm{Gaw}^{f}$ & BMI & $-0.006 \pm 0.005$ & 0.03 & 0.03 \\
\hline \multicolumn{5}{|c|}{$\begin{array}{l}\text { Data are presented as mean } \pm 95 \% \text { confidence interval. Vtg: thoracic gas } \\
\text { volume. \#: all predictors shown are significant at the } \mathrm{p}<0.05 \text { level and were } \\
\text { selected by stepwise procedure; }{ }^{~} \text { : effect sizes independent of each other; }{ }^{+} \text {: } \\
\text { independent proportion of variance explained by the predictor; }{ }^{\mathrm{s}} \text { : effect } \\
\text { measured in } \mathrm{L} ;{ }^{f} \text { : effect measured in } \mathrm{L} \cdot \mathrm{s}^{-1} \cdot \mathrm{cmH}_{2} \mathrm{O}^{-1} \text {. }\end{array}$} \\
\hline
\end{tabular}

females appear in table 2. Gaw, adjusted for asthma, was significantly associated with BMI, weight and $\mathrm{Vtg}$ in males, and with BMI and height in females. The results of multiple stepwise linear regressions for males and females appear in table 3. In males, after adjustment for current asthma and $\mathrm{Vtg}$, BMI correlated with Gaw (partial $\mathrm{r}^{2}=0.13$; $\mathrm{p}<0.0001$ ) with a decrease of $0.017 \mathrm{~L} \cdot \mathrm{s}^{-1} \cdot \mathrm{cmH}_{2} 0^{-1}$ per $\mathrm{kg} \cdot \mathrm{m}^{-2}$ increase in BMI. In females, after adjustment for asthma and $\mathrm{Vtg}$, BMI also correlated with Gaw, albeit weakly (partial $\mathrm{r}^{2}=0.03 ; \mathrm{p}=0.03$ ). Figures $1 \mathrm{a}$ and $\mathrm{b}$ show Gaw adjusted for lung volume and current asthma (Gaw residuals), from subjects grouped by increasing BMI, in males and females, respectively. The sex difference in the relationships between BMI and Gaw is shown.

\section{DISCUSSION}

The current authors studied the relationships between BMI, lung volume and airway calibre in a group of young adults aged 28-30 yrs. Compared with subjects in the normal weight range, lung volume and airway calibre were reduced in subjects with increasing BMI in a linear fashion. In addition, subjects in the underweight category $\left(<18.5 \mathrm{~kg} \cdot \mathrm{m}^{-2}\right)$ also had reduced airway calibre compared with normal weight subjects. However, increasing BMI was not associated with recent wheeze, AHR or current asthma. Analysis of the present data, which has the advantage of reflecting a population of very limited age range, shows that the reduction in airway calibre was only partly related to the reduction in lung volume and implicates other nonvolume-related mechanisms. The association between increasing BMI and decreasing airway calibre was stronger in males, being only weakly associated in females. To put the effects of obesity on airway calibre in perspective, a 26-yr-old, 70-kg male who is $178 \mathrm{~cm}$ in height (BMI $22 \mathrm{~kg} \cdot \mathrm{m}^{-2}$ ) has a predicted FRC of $3.36 \mathrm{~L}$ and predicted Gaw of $0.80 \mathrm{~L} \cdot \mathrm{s}^{-1} \cdot \mathrm{cmH}_{2} \mathrm{O}^{-1}$. If the same person had a BMI of $35 \mathrm{~kg} \cdot \mathrm{m}^{-2}$, based on the current data, FRC would be $2.13 \mathrm{~L}$ and Gaw $0.51 \mathrm{~L} \cdot \mathrm{s}^{-1} \cdot \mathrm{CmH}_{2} \mathrm{O}^{-1}$. In simplistic terms, this equates to an 


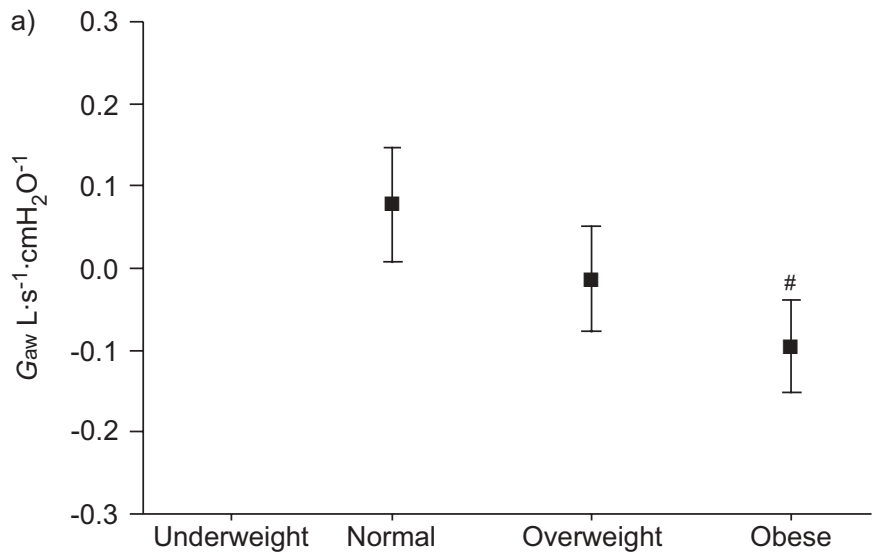

b)

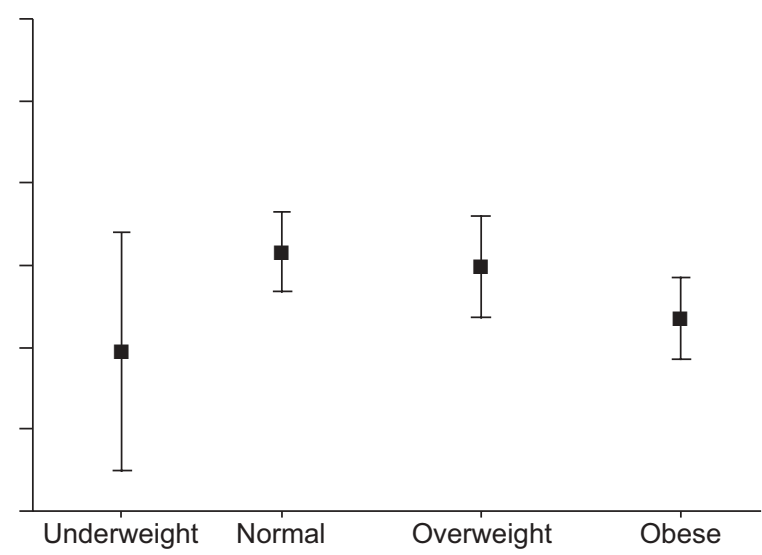

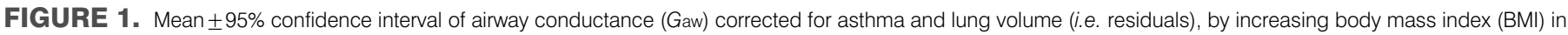

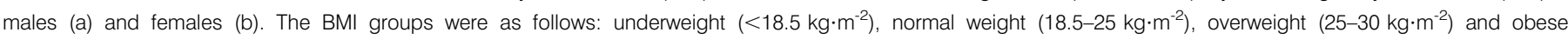

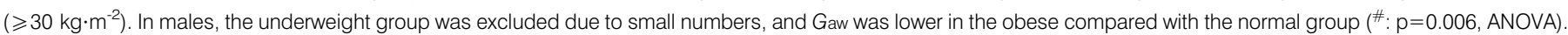
There were no significant differences between groups in females.

$11 \%$ reduction in diameter of a single 5-mm diameter airway and $58 \%$ increase in airway resistance, with only $10 \%$ of the increased resistance being due to the decreased lung volume.

The role of BMI in determining airway calibre, after adjustment for lung volume, has not been reported previously. Age and height, though not BMI, are parameters in predictive equations for Gaw [20], presumably because of the small numbers of subjects that were studied. In contrast to the current authors' results, ZERAH et al. [11] reported a strong relationship between Gaw and FRC with an $r^{2}$ of 0.49 in 46 healthy subjects, which explained the reduced airway calibre in obesity. However, their subjects ranged 16-63 yrs in age. RUBINSTEIN et al. [14] performed a case-control study of 103 obese subjects and 190 healthy, age-, sex- and height- matched controls over an age range of $\sim 60$ yrs. RUBENSTEIN et al. [14] also found that, in obese subjects, FRC was reduced but, after correction for this reduction in lung volume, Gaw was no different between groups. Interestingly, they also found reduced maximal expiratory flow rates in flow-volume curves at low lung volumes, which suggested the presence of peripheral airflow limitation in obese males.

The current study was unique in that a large sample from the general population that had a narrow age range of 28-30 yrs and a wide range of BMI was studied. These methodological characteristics were the likely factors that allowed the authors to find, in contrast to past studies, an association between obesity per se and airway narrowing. The narrow age range was probably the most important factor because lung elasticity decreases and obesity becomes more common with increasing age. Decreasing lung elasticity is the main factor causing the age-related reduction in airway calibre and it is, therefore, possible that the present findings in this age group may not be present in older populations, where lung elasticity may play a more dominant role in determining airway calibre. However, given the broadening distribution of BMI with ageing and the small magnitude of effect of BMI on airway calibre, a very large population sample would need to be studied to determine if the effect of BMI on airway calibre is applicable to the general population. So far such studies have not been carried out.

The present authors found sex differences in the relationship between obesity and both lung volumes and airway calibre, with a stronger relationship in males. This might be due to sex differences in body habitus, with greater central obesity in males and/or differences in muscle mass. Central obesity may exert different mechanical stresses on the respiratory system, which might alter the vertical gradients in transpulmonary pressures. However, central obesity may elevate the diaphragm and reduce airway length, which would reduce airway resistance. These effects were observed in males who had normal or higher BMI, since there were insufficient numbers of underweight males to analyse the effects of BMI on airway calibre in this category, although the current authors did find airway calibre tended to be less in underweight females (fig. 1). This association has previously been found in the underweight group $[8,22]$ who were found to use more medications and report more symptoms. The underlying mechanisms are not understood, but it could potentially relate to low function at birth, particularly in low birthweight babies in whom reduced lung function may persist into older life, lung injury from smoking or other environmental influences during airway growth in childhood, or to genetic factors. The sex differences in lung and chest-wall shapes could be relevant because potential differences in airway configurations have differential effects on Gaw measurements due to the physical properties of fluid flow through tubes [23].

There are several possible explanations for airways being narrower in obesity. There could have been obesity-related changes to the structure and function of airway walls, airway smooth muscle, lung parenchyma and the upper airway. Chronic reduction in end-expiratory lung volume may cause micro-atelectasis [9]. This would have the effect of further reducing lung volume, but it would increase the elastic recoil of the lungs and thereby increase airway calibre. Breathing at low lung volume has several possible effects on the airways. Airway smooth muscle has a large capacity to mechanically 
adapt to shorter length, so that its force-generating ability is maximised by either plastic adaptation [24, 25] or changes in the metabolism of the actin/myosin mechanism [26] leading to chronic narrowing. Having chronic low lung volume could also cause remodelling in the airway wall, either due to reorganisation of the matrix or perhaps due to processes unique to obesity itself, which might cause airway wall thickening. There are also biochemical changes that are associated with obesity, such as increased leptin and interleukin-6 levels [27], which may either drive or contribute to changes in airway structure and function.

The current authors found no association between AHR or wheeze, or their combination, and obesity in the study population. In contrast, small effects of obesity on the prevalence of doctor-diagnosed asthma in other large population studies have been found and, in particular, self-reported wheeze $[1,6,8]$. However, the absence of any association between AHR and obesity is consistent with previous findings in Australian adults [8]. This apparent discrepancy in findings is most probably due to the relatively small numbers of subjects in this study. The small size effect of obesity on wheeze was statistically significant in the previous studies because they involved thousands of subjects. The present authors found a prevalence of recent wheeze in $28 \%$ of subjects who had BMIs of $\leqslant 25 \mathrm{~kg} \cdot \mathrm{m}^{-2}$ compared with $31 \%$ in those who had greater BMIs, which was not significantly different.

The prevalence of obesity in the current study population was $20 \%$, which is likely to be higher than in the populations used to calculate the normal values, but is similar to the prevalence reported elsewhere in Australia [28] and in other Western countries [29]. An implication of the present findings is that, with increasing obesity in Western populations, the current predicted values for Gaw are likely to be too high for patients with high BMI who are an increasing proportion of the general population. Thus, BMI should be included as a factor in future equations predicting specific conductance.

In conclusion, a strong relationship was found between body mass index and both lung volume and airway calibre in nonunderweight individuals. It was found that, with increasing body mass index, airways were narrower than expected on the basis of the reduction in lung volume, suggesting that there were structural or functional changes in the airways that were specifically associated with increasing body mass index. The results of this study provide strong support for further studies to elucidate the mechanisms of the airway narrowing, which would allow clinicians to better assess respiratory symptoms associated with obesity as opposed to airway narrowing due to asthma.

\section{ACKNOWLEDGEMENTS}

The authors would like to thank the members of the Belmont Cohort, New South Wales, Australia, for their continuing commitment in participating in this study.

\section{REFERENCES}

1 Camargo CA Jr, Weiss ST, Zhang S, Willett WC, Speizer FE. Prospective study of body mass index, weight change, and risk of adult-onset asthma in women. Arch Intern Med 1999; 159: 2582-2588.
2 Celedon JC, Palmer LJ, Litonjua AA, et al. Body mass index and asthma in adults in families of subjects with asthma in Anqing, China. Am J Respir Crit Care Med 2001; 164: 1835-1840.

3 Chinn S, Jarvis D, Burney P, European Community Respiratory Health Survey, Relation of bronchial responsiveness to body mass index in the ECRHS. European Community Respiratory Health Survey. Thorax 2002; 57: 1028-1033.

4 Lewis S, Britton J. High body mass index is associated with wheezing rather than asthma. Am J Respir Crit Care Med 2000; 161: A497.

5 Litonjua AA, Sparrow D, Celedon JC, DeMolles D, Weiss ST. Association of body mass index with the development of methacholine airway hyperresponsiveness in men: the Normative Aging Study. Thorax 2002; 57: 581-585.

6 Shaheen SO, Sterne JA, Montgomery SM, Azima H. Birth weight, body mass index and asthma in young adults. Thorax 1999; 54: 396-402.

7 von Mutius E, Schwartz J, Neas LM, Dockery D, Weiss ST. Relation of body mass index to asthma and atopy in children: the National Health and Nutrition Examination Study III. Thorax 2001; 56: 835-838.

8 Schachter LM, Salome CM, Peat JK, Woolcock AJ. Obesity is a risk for asthma and wheeze but not airway hyperresponsiveness. Thorax 2001; 56: 4-8.

9 Pelosi P, Croci M, Ravagnan I, et al. The effects of body mass on lung volumes, respiratory mechanics, and gas exchange during general anesthesia. Anesth Analg 1998; 87: 654-660.

10 Cotes JE, Chinn DJ, Reed JW. Body mass, fat percentage, and fat free mass as reference variables for lung function: effects on terms for age and sex. Thorax 2001; 56: 839-844.

11 Zerah F, Harf A, Perlemuter L, Lorino H, Lorino AM, Atlan G. Effects of obesity on respiratory resistance. Chest 1993; 103: 1470-1476.

12 Yap JC, Watson RA, Gilbey S, Pride NB. Effects of posture on respiratory mechanics in obesity. J App Physiol 1995; 79: 1199-1205.

13 Vincent NJ, Knudson R, Leith DE, Macklem PT, Mead J. Factors influencing pulmonary resistance. J Appl Physiol 1970; 29: 236-243.

14 Rubinstein I, Zamel N, DuBarry L, Hoffstein V. Airflow limitation in morbidly obese, nonsmoking men. Ann Intern Med 1990; 112: 828-832.

15 Peat JK, van den Berg RH, Green WF, Mellis CM, Leeder SR, Woolcock AJ. Changing prevalence of asthma in Australian children. BMJ 1994; 308: 1591-1596.

16 Peat JK, Britton WJ, Salome C, Woolcock AJ. Bronchial hyperresponsiveness in two populations of Australian schoolchildren. III. Effect of exposure to environmental allergens. Clin Allergy 1987; 17: 291-300.

17 Yan K, Salome CM, Woolcock AJ. Rapid method for measurement of bronchial responsiveness. Thorax 1983; 38: 760-765.

18 Knudson RJ, Lebowitz MD, Holberg CJ, Burrows B. Changes in the normal maximal expiratory flow-volume curve with growth and aging. Am Rev Respir Dis 1983; 127: 725-734. 
19 Crapo RO, Morris AH, Clayton PD, Nixon CR. Lung volumes in healthy nonsmoking adults. Bull Eur Physiopath Respir 1982; 18: 419-425.

20 Briscoe W, DuBois A. The relationship between airway resistance, airway conductance, and lung volumes in subjects of different age and body size. J Clin Investig 1959; 37: 1279-1285.

21 Toelle BG, Peat JK, van den Berg RH, Dermand J, Woolcock AJ. Comparison of three definitions of asthma: a longitudinal perspective. J Asthma 1997; 34: 161-167.

22 Sin DD, Jones RL, Man SF. Obesity is a risk factor for dyspnea but not for airflow obstruction. Arch Intern Med 2002; 162: 1477-1481.

23 Thorpe CW, Bates JH. Effect of stochastic heterogeneity on lung impedance during acute bronchoconstriction: a model analysis. J Appl Physiol 1997; 82: 1616-1625.

24 Gunst SJ, Meiss RA, Wu MF, Rowe M. Mechanisms for the mechanical plasticity of tracheal smooth muscle. Am J Physiol 1995; 268: C1267-C1276.
25 Wang L, Paré PD, Seow CY. Effects of length oscillation on the subsequent force development in swine tracheal smooth muscle. J Appl Physiol 2000; 88: 2246-2250.

26 Fredberg J, Inouye D, Mijailovich M, Butler J. Perturbed equilibrium of myosin binding in airway smooth muscle and its implications in bronchospasm. Am J Respir Crit Care Med 1999; 159: 959-967.

27 Bastard JP, Jardel C, Delattre J, Hainque B, Bruckert E, Oberlin F. Evidence for a link between adipose tissue interleukin-6 content and serum C-reactive protein concentrations in obese subjects. Circulation 1999; 99: 2221-2222.

28 Cameron AJ, Welborn TA, Zimmet PZ, et al. Overweight and obesity in Australia: the 1999-2000 Australian Diabetes, Obesity and Lifestyle Study (AusDiab). Med J Aus 2003; 178: 427-432.

29 Flegal KM, Carroll MD, Ogden CL, Johnson CL. Prevalence and trends in obesity among US adults, 19992000. JAMA 2002; 288: 1723-1727. 